\title{
UN EPISODIO EN EL CONFLICTO REALENGO-ABADENGO \\ DURANTE EL REINADO DE SANCHO IV \\ EL CUADERNO DE PESQUISA DE SEGOVIA DE $1287^{1}$
}

\author{
BONIFACIO BARTOLOMÉ HERRERO \\ Universidad Complutense de Madrid
}

\section{SUMARIO}

1. Introducción.- 2. El conflicto realengo-abadengo durante el reinado de Sancho IV.- 3. El cuaderno de pesquisa de Segovia de 1287.- 4. Conclusiones.- 5. Apéndice.

\section{INTRODUCCIÓN}

Una de las constantes durante toda la Edad Media castellana fue sin duda la tensión existente entre la jurisdicción eclesiástica y la laica, bien fuera ésta real, nobiliaria o concejil. Dentro de esta situación general se inscribe el conflicto realengo-abadengo, que enfrentaba a la corona, a los eclesiásticos y a los concejos por cuestiones de carácter jurisdiccional que tenían implicaciones directas en el ámbito económico².

\footnotetext{
'Este trabajo ha sido realizado en el marco del proyecto de investigación "Propaganda y legitimación en los orígenes de la monarquía hispánica (ca. 1400-ca. 1520): Una visión multidisciplinar" (PR 218/94-5686/94), dirigido por el Prof. Dr. José Manuel Nieto Soria, y patrocinado por la Universidad Complutense de Madrid.

'Para una visión general del problema, A. ARRANZ GUZMÁN, El tercer estado castellano ante las relaciones realengo-abadengo. Siglos XIII-XV, "Hispania", XLIX (1989), pp. 443-76; y también Reconstrucción y verificación de las Cortes Castellano-Leonesas: La participación del clero, "En la España Medieval”, 13 (1990), pp. 33-132. Además, J.M. NiETo SORIA, Abadengo

"Anuario de Estudios Medievales", 27 (1997)
} 
Desde muy antiguo, las instituciones religiosas habían sido favorecidas por los laicos, y especialmente por la monarquía, con continuas y significativas donaciones materiales. Durante el siglo XII la magnitud y la extensión de estas donaciones había desembocado en muchos casos en la formación de sólidos señoríos eclesiásticos. La existencia de estos señoríos no supuso nunca un problema de entidad, al menos en cuanto a su reconocimiento como jurisdicción independiente, pero en cambio sí resultó mucho más conflictiva la acumulación progresiva que las instituciones eclesiásticas realizaban de bienes inmuebles urbanos y rurales por medio de compras, trueques o donaciones, ya que su integración en el abadengo los convertía en la práctica en no enajenables, además de quedar exentos en la mayoría de los casos de pechos reales y concejiles ${ }^{3}$. A mediados del siglo XIII el volumen de bienes integrados en la jurisdicción eclesiástica era ya muy grande, a lo que se sumaba el hecho de que no dejaba de aumentar, con el consiguiente perjuicio para la hacienda y la autoridad regia, y para la economía de los pujantes concejos castellanos.

La conflictividad entre el realengo y el abadengo se desató definitivamente durante el reinado de Alfonso X. La primera pesquisa de alcance, que denotaba un claro interés de la monarquía por dominar el avance que el abadengo estaba experimentando a costa del realengo, la inició el rey Sabio en 1258. No parece que tuviera ningún efecto inmediato, pero al menos supuso una llamada de atención para las instituciones eclesiásticas que hasta el momento adquirían tierras realengas sin apenas limitaciones. En 1278, veinte años después de la primera, se produjo una segunda pesquisa que pretendía también la localización de los bienes que hubieran pasado inadecuadamente del realengo al abadengo para posteriormente restituirlos a su situación original, y que tampoco parece que lograra el efecto deseado ${ }^{4}$. Entre las dos investigaciones se registra también la primera denuncia en cortes del tercer estado relativa al abadengo. No cabe duda de que los concejos ya venían considerando desde tiempo atrás el aumento del abadengo

episcopal y realengo en tiempos de Alfonso XI de Castilla, "En la España Medieval", 5 (1984), pp. 709-736.

${ }^{3}$ Para una visión de conjunto de las características de la propiedad eclesiástica y de su problemática durante la Edad Media, M.G. MORENO ANTÓN, La enajenación de bienes eclesiásticos en el ordenamiento jurídico español, Salamanca, 1987, pp. 61-64.

${ }^{4}$ J.M. NiETo SORIA, Iglesia y poder real en Castilla. El episcopado, 1250-1350, Madrid, 1988, pp. 139-40. 
con cierta preocupación, pero es posible que la actuación frente al problema por parte de Alfonso X y el clima político del momento les animase a explicitar el perjuicio que para ellos suponía la continua disminución de las heredades pecheras, como así hicieron los representantes del concejo de Burgos en las cortes de Jerez de $1268^{5}$.

De este modo, a finales del reinado de Alfonso $\mathrm{X}$ el conflicto realengo-abadengo ya se hallaba plenamente definido, con todos los participantes en el mismo preparados para defender activamente sus intereses y $\sin$ una perspectiva de solución inmediata.

\section{EL CONFLICTO REALENGO-ABADENGO DURANTE EL REINADO DE SANCHO IV}

Cuando Sancho IV accedió al trono sin duda consideraba como uno de los problemas prioritarios de la política interior el fortalecimiento de la autoridad real, tan disminuida en los últimos años del reinado de su padre ${ }^{6}$. Este proyecto habría de pasar ineludiblemente por la consolidación del realengo, cuyo deterioro podía limitar considerablemente la capacidad de acción del monarca. De este modo, Sancho IV hizo suya la política que iniciara su padre Alfonso $\mathrm{X}$ de limitar las donaciones de bienes inmuebles a las instituciones eclesiásticas, sustituyéndolas por donaciones de rentas, y de recuperar tierras de realengo integradas en el abadengo mediante su permuta también por rentas reales. En este sentido Jose Manuel Nieto ha constatado para el reinado de don Sancho tan solo cinco donaciones de bienes inmuebles que tuvieran a prelados como beneficiarios ${ }^{7}$. Sin embargo, las medidas más importantes respecto a este problema serían adoptadas en las reuniones de cortes, de las que se celebrarían seis durante este reinado, ya que la intención del nuevo monarca no era sólo la de limitar el crecimien-

\footnotetext{
${ }^{5}$ A. ARRANZ Guzmán, El tercer estado castellano, p. 445.

${ }^{6} \mathrm{El}$ estudio fundamental sobre Sancho IV es el de M. GaIBROIS DE BALLESTEROS, Historia del reinado de Sancho IV de Castilla, 3 vols., Madrid, 1922-28. Una puesta al día de las circunstancias de este reinado pueden encontrarse en J.M. NIETO SORIA, Sancho IV (12841295), Palencia, 1994.

${ }^{7}$ J.M. NIETO SORIA, Iglesia y poder real, p. 99.
} 
to del abadengo, sino la de lograr la devolución de los bienes que se hubieran integrado en éste procedentes del realengo ${ }^{8}$.

No se conservan las actas de las primeras cortes del reinado, las celebradas en Sevilla en 1284. En todo caso, Sancho IV buscaba en éstas la aceptación general de su autoridad y centró su atención en la adopción de una serie de medidas para reforzar la defensa de la frontera con los musulmanes, no existiendo constancia de que se tratara allí el problema del abadengo ${ }^{9}$. Tampoco han llegado hasta nosotros los ordenamientos de las cortes de Burgos de 1285, pero sin embargo existe constancia documental de que en ellas fue tratado el asunto del aumento del abadengo a costa del realengo ${ }^{10}$. Es muy posible además que fuera en estas cortes donde se iniciara la pesquisa que Sancho IV ordenó hacer sobre este asunto ${ }^{11}$. El ordenamiento de las cortes de Palencia de 1286 recoge la circunstancia de que la pesquisa ya estaba en marcha y el monarca esperaba los resultados de la misma para actuar en consecuencia ${ }^{12}$. El ordenamiento de las cortes celebradas a continuación, las de Toro de 1287, se ha perdido, pero considerando la evolución de los acontecimientos resulta inevitable pensar que en ellas se trataría el tema que nos ocupa. En este caso resulta especialmente lamentable que no se conserven datos sobre el contenido de las reuniones, pues desde este momento se observa un cambio de orientación

\footnotetext{
${ }^{8}$ M. GaIBROIS, op. cit., II, p. 161, nota 1, indica que "en nuestro estudio, en preparación, sobre la vida interna del reinado de Sancho IV, trataremos con más extensión el interesante asunto del realengo y el abadengo". No tengo constancia de que este trabajo llegara a publicarse, ni de que exista alguno similar, razón por la cual expongo aquí la evolución general del problema.

${ }^{9}$ S. de Moxó, Sancho IV y Fernando IV, "Historia de España", (dir. R. Menéndez Pidal), tomo XIII-1, Madrid, 1990, pp. 209-210

${ }^{10} \mathrm{En}$ un documento real expedido en Toro el 12 de septiembre de 1287 se hace referencia al "ordenamiento que nos fiziemos quando fiziemos las cortes en Burgos en razon del rengalengo e del abadengo". Archivo Histórico Nacional, clero, pergaminos, carpeta 1977, $\mathrm{n}^{\circ}$ 12. Ed. M. Gaibrois DE Ballesteros, op. cit., III, doc. 173, pp. CIV-CV.

"Así podría desprenderse de la cláusula que incluyen los pesquisidores que actuaron en Segovia en 1287 y que dice así: "que vala su derecho si algunos heredamientos pasaron de abadengo a rrengalengo por conpra o en otra manera del tiempo antes que el rey dio la sentencia en Burgos". El paso ha de ser evidentemente de realengo a abadengo, este cambio de términos se debe sin duda a un error del escribano, pero lo importante es que el tono denota un antes y un después de las cortes de Burgos de 1285, cuyo corte podría estar producido precisamente por el mandamiento de realizar la pesquisa.

12"Et otrossi tengo por bien de non tomar ninguna cosa dela pesquisa que mande ffazer ssobrel rengalengo e el abadengo e las bien ffetrias ffasta quela yovea e la libre commo fallare por derecho". Cortes de los antiguos reinos de León y de Castilla, ed. de la Real Academia de la Historia, I, Madrid, 1861, p. 98, petición 11.
} 
en la política real respecto del realengo y el abadengo, plasmado en la expedición de documentos a diversas instituciones eclesiásticas, eximiéndolas de pechar por los bienes que tuvieran procedentes del realengo ${ }^{13}$. Las cortes de Haro de 1288 significarán la consolidación de la tendencia ya señalada y marcarán las pautas que seguirá la política de Sancho IV durante el resto del reinado. En esta reunión se separó al judío Abraham el Barchilón del arrendamiento de las rentas reales, apartamiento que entre otras consideraciones significaba el abandono de la política fiscal intentada por el monarca los primeros años de su reinado. Al mismo tiempo, se dio por finalizada la pesquisa iniciada en 1285 , saldándose así con un relativo fracaso la política real de fortalecimiento del realengo ${ }^{14}$. Tras estas cortes de nuevo aparecen documentos de exención de pago para bienes de realengo que hubieran pasado al abadengo, en consonancia con la actitud que Sancho IV había adoptado definitivamente sobre el asunto ${ }^{15}$. En las últimas cortes del reinado, las de Valladolid de 1293 , hay un pequeño episodio que ilustra perfectamente cual era la posición que para estas fechas mantenía el monarca. En esta asamblea los reinos de Castilla y de León recibieron sus ordenamientos por separado. Mientras en el castellano no había ninguna referencia al abadengo, en el leonés se recogía que ni prelados ni nobles pudieran comprar del realengo si no era con la condición de que pechasen como un vecino más ${ }^{16}$. Paralelamente, el mismo Sancho IV expedía un documento al concejo de León en el que permitía a éste recuperar para el realengo lo que del mismo hubiera pasado al abadengo, pero sólo en el caso de que las instituciones eclesiásticas careciesen de privilegios para efectuar estas adquisiciones, condición que, de hecho, reducía la orden regia practicamente a la inoperancia ${ }^{17}$.

\footnotetext{
${ }^{13}$ Cito aquí los recogidos por M. GaIBROIS DE BALLESTEROS en $o p$. cit., III, para el período que abarca de las cortes de Toro de 1287 a las de Haro de 1288: doc. 170, (1287-VIII-15), al arzobispado de Toledo; doc. 172, (1287-VIII-17), al monasterio de San Román de Entrepeñas; doc. 173, (1287-IX-12), al monasterio de Santa María de los Huertos de Segovia; doc. 182 (1288-II-14), al monasterio de Aguilar de Campoo; doc. 185, (1288-III-5), al monasterio de Sahagún; doc. 193, (1288-IV-12), al monasterio de San Miguel de Escalada; doc. 196, (1288IV-26), al obispo y cabildo catedralicio de Burgos; y doc. 202, (1288-V-28), a la diócesis de Zamora.

${ }^{14}$ Cortes de los antiguos reinos de León y de Castilla, I, p. 101, peticiones 1 y 2.

${ }^{15} \mathrm{M}$. Gaibrois De BALLESTEROS, op. cit., III, doc. 319, (1290-IX-6), al arcedianazgo de Talavera; y doc. 321, (1290-IX-20), a los clérigos de Salamanca y Ciudad Rodrigo.

${ }^{16}$ Cortes de los antiguos reinos de León y de Castilla, I, pp. 119-20, petición 3.

${ }^{17} \mathrm{M}$. Gaibrois DE BALLESTEROS, op. cit., III, doc. 472, (1293-V-14).
} 
La pérdida de voluntad que Sancho IV exhibía por controlar el crecimiento del abadengo desde 1288 debió convencer a los concejos de que si querían obtener algunos logros al respecto debían ser ellos mismos quienes actuasen directamente, de modo que en los últimos años del reinado el monarca debió intervenir, paradojicamente, para salvaguardar la integridad de los abadengos que eran ocupados por concejos y otros particulares ${ }^{18}$.

\section{El CUADERNO DE PESQUiSA DE SEgOVIA DE 1287}

Como consecuencia de la pesquisa ordenada por Sancho IV en 1285 para todo el reino sobre los bienes que habían pasado del realengo al abadengo, se recogía el 26 de agosto de 1287 la información contenida al respecto en los registros de algunos de los escribanos de la ciudad de Segovia ${ }^{19}$.

Antes de entrar a considerar el contenido del cuaderno merece la pena detenerse en la mecánica de la pesquisa, que es de suponer que fuera muy similar a la de las que se estaban realizando en los otros lugares del reino. Los encargados directos de la investigación eran los pesquisidores, en este caso Ferrán Muñiz y Ferrán Alcher, que actuaban por delegación de Lope García de Vitoria, que junto a Martín Pérez de Burgos eran, en palabras de Sancho IV, "nuestros omes que arrendaron todas las demandas de don Abraham el Barchilon que nos aviemos contra todos aquellos que alguna cosa tomaron o conpraron o camiaron o les fue dado del nuestro rengalengo"20. La función principal de Ferrán Muñiz y su compañero fue

\footnotetext{
${ }^{18}$ J.M. NIETO SORIA, Iglesia y poder real, p. 141.

${ }^{19}$ Archivo Catedralicio de Segovia, cajas, G-37. Se trata de un cuaderno en papel con seis hojas más seis en blanco, que recoge en primer lugar la pesquisa propiamente dicha, y después la adjudicación en favor de los arrendadores de rentas reales de diversos bienes pertenecientes a instituciones eclesiásticas. Fue publicado parcialmente por J.A. RUIZ HERNANDO en su Historia del urbanismo en la ciudad de Segovia del siglo XII al XIX, Segovia, 1982, II, pp. 262264 , que utilizó la abundante información que el documento proporciona sobre bienes inmuebles en la ciudad.

${ }^{20}$ (1287-IX-12, Toro). Archivo Histórico Nacional, clero, pergaminos, carpeta 1977, $\mathrm{n}^{\circ} 12$. Ed. M. GaIBROIS DE BALleSTEROS, op. cit., III, doc. 173, pp. CIV-CV.

El pesquisidor Ferrán Alcher y el entregador Diego Gil, al que se citará más adelante, eran dos importantes caballeros villanos segovianos. J. MARTínEZ MORO, La Tierra en la Comunidad de Segovia. Un proyecto señorial urbano (1088-1500), Valladolid, 1985, pp. 138-139. La participación de dos miembros destacados del concejo segoviano en la pesquisa real ilustra a la perfección la receptividad y el apoyo que la política de Sancho IV sobre el abadengo encontró
} 
la de supervisar la exactitud de los documentos extraidos de los registros de ciertos escribanos de la ciudad de Segovia, se identifica a dos de ellos Pedro Pérez y Miguel Pérez, documentos que reflejaban la compra, permuta o donación de bienes inmuebles en los que hubieran participado instituciones religiosas. En el cuaderno se recogían los datos esenciales de cada documento, no se realizaba un traslado íntegro de los mismos. Este sistema de recogida de la información tenía dos ventajas principales. La primera era la rapidez con que permitía obtener la información deseada, pues al acudir a los escribanos, ante quienes debían realizarse todos los movimientos de bienes inmuebles, se evitaba el tener que recorrer una a una catedrales, monasterios, conventos y parroquias en busca de los documentos deseados. La segunda era que evitaba precisamente los impedimentos y ocultaciones que estas instituciones efectuarían de exigírlas a ellas la presentación de los documentos. Como se puede apreciar, este sistema permitía sobre todo determinar las pérdidas que el realengo había sufrido en un determinado lugar, independientemente de la institución a la que hubieran ido a parar esos bienes $^{21}$. Aunque lo más frecuente era que los cabildos o los monasterios, por ejemplo, concentraran la mayor parte de sus propiedades en su entorno más inmediato, no resultaba en absoluto infrecuente que gozaran de propiedades urbanas o rurales en ámbitos geográficos muy alejados de su lugar de asentamiento. Una buena coordinación de las pesquisas hubiera permitido salvar esta dificultad y llegado el momento presentar a cada institución una relación exhaustiva de los bienes que debía devolver, independientemente del lugar donde se encontraran éstos. Sin embargo, una investigación de esta envergadura hubiera necesitado la aportación de un gran número de medios materiales y humanos que sólo se habrían justificado en el caso de existir la certeza de que los datos aportados por la pesquisa tendrían finalmente una aplicación práctica, algo en lo que no parece que nadie tuviera demasiada confianza. Una vez recogida en la pesquisa la información deseada ésta era estudiada por ciertos delegados reales, los entregadores, identificados en este caso como Diego Gil y Gutierre García,

\footnotetext{
entre las ciudades castellanas, cuyos dirigentes fueron precisamente los encargados de llevar a cabo la investigación

${ }^{21}$ Esto no es exactamente así puesto que como se puede comprobar facilmente los escribanos públicos de una ciudad como Segovia redactaban documentos sobre bienes ubicados en otras muchas poblaciones, pero que sin embargo en la mayoría de los casos no rebasaban los límites de la tierra de Segovia o de la diócesis, con lo que en general se puede constatar un cierto agrupamiento geográfico.
} 
que eran quienes siguiendo unos criterios fijados de antemano dividían los bienes inmuebles en dos grupos, los que podían permanecer en el abadengo y los que debían volver al realengo. De estos últimos se expedía carta de propiedad a los arrendadores de las rentas reales, los arriba mencionados Lope García de Vitoria y Martín Pérez de Burgos, especificándose dos tipos de situaciones, aquellas en las que el bien pasaba a ellos "por cierto por que lo avedes de aver", y aquellas otras en las que no podrían acceder finalmente a la propiedad si los que gozaban de ella en aquel momento "mostraren alguna rraçon por que lo non devades aver".

El cuaderno de pesquisa de Segovia recoge veintidós documentos y siete noticias de bienes inmuebles pertenecientes a diversas instituciones eclesiásticas de la ciudad y la diócesis de Segovia adquiridos por éstas mediante compra, donación o legado testamentario entre los años 1276 y 1287. En la ciudad se recogen bienes del cabildo catedralicio, del cabildo de clérigos, de las iglesias parroquiales de San Miguel, San Nicolás y Santiago, de los monasterios de Santa María de los Huertos, San Vicente y Santo Domingo y de las cofradías de San Blas y San Francisco ${ }^{22}$. En la diócesis refleja posesiones de los cabildos de clérigos de los sexmos de San Lorenzo y Santa Eulalia y del monasterio de Párraces.

La entrega de bienes a Lope García y Martín Pérez recogida en el cuaderno afectó en la ciudad al cabildo catedralicio, a las iglesias parroquiales de San Andrés, San Facundo, San Justo y San Miguel y a los monasterios de Santa María de los Huertos y San Vicente; en la diócesis a los cabildos de clérigos de los sexmos de San Lorenzo y la Trinidad, y fuera de la diócesis a los ffrayles de Sanctiago ${ }^{23}$.

Una de las circunstancias que más llama la atención tras la lectura del cuaderno es que de las veintinueve propiedades citadas en la pesquisa sólo una aparece en el documento de entrega de bienes. Por un lado, esto viene a confirmar el hecho de que en el presente cuaderno sólo se revisaron los registros de algunos de los escribanos públicos que había en la ciudad de

\footnotetext{
${ }^{22}$ Esta es la primera noticia conocida de las cofradías de San Blas y San Francisco. Este documento también nos ofrece una primera referencia de otra cofradía más, al citar como linderos de una casa junto a la puerta de Santiago, otra perteneciente a "los cofradres de Sant Andres". Cuaderno de pesquisa, fols. 2 r., 2 v., y 3 r

${ }^{23}$ Esta noticia documental es la primera que nos indica la existencia de posesiones de la orden de Santiago en la ciudad de Segovia. Se trataba de unas casas situadas en la colación de San Sebastián, lindantes con la muralla, y que según el cuaderno habían sido entregadas en donación a la mencionada orden militar. Cuaderno de pesquisa, fol. $5 \mathrm{r}$.
} 
Segovia, probablemente de tres de ellos de los que de dos se cita el nombre. De este modo, es posible que sobre los registros del resto de escribanos de la ciudad se hubieran realizado investigaciones similares y paralelas que no se hayan conservado ${ }^{24}$. Por otro lado, la circunstancia mencionada parece indicar que a pesar de la pesquisa muchos de los bienes eclesiásticos no sufrieron ningún peligro de volver al realengo, aunque hay que mantener la reserva de que existieran otros documentos de entrega de bienes que no se hayan conservado. En todo caso, esta es una cuestión que no puede ser aclarada sin conocer cuales eran los criterios que se establecieron para el retorno de los bienes de abadengo al realengo, algo que hasta el momento resulta practicamente desconocido.

También se puede destacar que de las propiedades entregadas, catorce, la mitad lo fueran de un modo definitivo y la otra mitad dependiendo de los derechos de sus propietarios. No se sabe con certeza cual era el criterio que diferenciaba las entregas definitivas de las condicionadas, aunque resulta clarificador que de las mencionadas siete entregas definitivas cinco afectasen a iglesias parroquiales de la ciudad, una al cabildo de clérigos del sexmo de San Lorenzo y la restante al monasterio de Santa María de los Huertos. Como se puede apreciar fue el clero parroquial, en definitiva el bajo clero, el que resultó más perjudicado con la pesquisa. Esto también refleja la escasa influencia de que gozaban las parroquias y los cabildos parroquiales, pues con esta actitud de los oficiales reales se puede adivinar que estas instituciones carecían de privilegios y exenciones de importancia con los que pudieran basar una apelación que les permitiera retener la propiedad de los bienes mencionados.

La composición de los bienes que recogen tanto la pesquisa como el documento de entrega nos reflejan que aproximadamente un tercio de los mismos eran casas. De este modo, la rentabilidad de las propiedades urbanas debía ser grande, pues su valor de adquisición era muy similar al de las propiedades rurales y mientras que éstas admitían diversos modos de explotación que podían modificarse en cuestión de la coyuntura, el único beneficio que se podía obtener con las primeras era el derivado de su entrega en arrendamiento. La distribución geográfica de los bienes denota una cierta dispersión de los mismos, aunque en la mayoría de los casos se encontrasen

\footnotetext{
${ }^{24}$ Como ya se ha dicho, de los catorce bienes entregados sólo uno aparece en el cuaderno de pesquisa. Los trece restantes debieron ser recogidos de algún modo, y parece razonable pensar que se hubieran reunido a través de otras pesquisas realizadas al mismo tiempo.
} 
dentro de la diócesis segoviana ${ }^{25}$. El cuaderno también ofrece información sobre el momento en el que se realizaban preferentemente las transacciones, dato que sin ser logicamente extrapolable sí tiene su interés al abarçar la información del cuaderno un período de once años. De este modo, en los meses de abril y mayo se registran nueve de las veinte operaciones de las que conocemos su mes de realización ${ }^{26}$. Por último, quisiera hacer notar la importancia que para esta época tenían todavía las donaciones de particulares a las instituciones religiosas. De los veintidós documentos recogidos en el cuaderno, seis eran donaciones, de las que cuatro tuvieron como beneficiario al monasterio de San Vicente, una al de Santa María de los Huertos y la restante a la iglesia parroquial de Santiago. Esta circunstancia permite entrever la importancia que para las distintas instituciones tenía el mantenimiento de la estima de los laicos, estima que con cierta probabilidad habría de plasmarse en la entrega a las citadas instituciones de bienes cuya importancia dependía de la posición del donante pero que sin duda serían bien recibidos en todos los casos.

La reacción de los eclesiásticos segovianos a la pesquisa sobre sus bienes fue inmediata. El 12 de septiembre de 1287, apenas dos semanas después de realizada la investigación en Segovia, el monasterio de Santa María de los Huertos obtenía de Sancho IV la posesión definitiva y libre de todo pecho de los bienes que tenía procedentes del realengo. Pero esta protección no le resultó gratuita, sólo la consiguió después de que acordara con Lope García de Vitoria y Martín Pérez de Burgos la entrega a éstos de cinco mil maravedíes, una considerable cantidad que Abraham el Barchilón dio por buena ante el monarca con lo que se ponía fin al asunto ${ }^{27}$. El 26 de septiembre el monarca escribía a los entregadores del realengo y del

\footnotetext{
${ }^{25}$ Dentro de la diócesis las propiedades aparecen ubicadas en: Açedos de Parrazes, Escalona del Prado, Fajejas, La Lastra, Lomiello de Parrazes, La Matiella de Valsequiella, Marazoleja, Muñopedro, Oter Redondo, Sant Ovennia, Segovia y Valsequiella. Fuera de ella en: Eça, Lozoya, Morata y Monesterio de Tajunna.

${ }^{26} \mathrm{La}$ distribución de los documentos se realiza de este modo: enero, ninguno; febrero, 2; marzo, 1; abril, 6; mayo, 3; junio, ninguno; julio, ninguno; agosto, 1; septiembre, 3; octubre, 1 ; noviembre, 2 ; y diciembre, 1 . No he pretendido aquí más que ofrecer algunas reflexiones sobre el contenido de los documentos recogidos en el cuaderno de pesquisa, pues profundizar en los mismos excede los objetivos del presente trabajo. Para situarlos en su adecuado contexto ver A. García Sanz, J.L. Martín, J.A. Pascual y V. Pérez Moreda, Propiedades del cabildo segoviano, sistemas de cultivo y modos de explotación de la tierra a fines del siglo XIII, Salamanca, 1981.

${ }^{27}$ (1287-IX-12, Toro), Archivo Histórico Nacional, clero, pergaminos, carpeta 1977, nº 12. Ed. M. Gaibrois DE BAllesteros op. cit., III, doc. 173, pp. CIV-CV.
} 
abadengo en el obispado de Segovia recogiendo la queja del cabildo catedralicio de que no respetaban los privilegios que tenían de los reyes anteriores, ni las donaciones que poseían hasta Fernando III, les tomaban los heredamientos protegidos por privilegios e iban más allá de lo que estipulaba el quaderno "del mio ordenamiento que vos tenedes en esta rrazon seellado con mio seello colgado e contra las mis cartas que traedes sobresto". Sancho IV ordena a los entregadores que respetaran los privilegios de que gozaba el cabildo, indicando que en caso de duda le remitieran la documentación personalmente a él y mientras tanto no hicieran nada más ${ }^{28}$. Cuatro días después, el 30 de septiembre, el monarca escribía al alcalde real Domingo Núñez de Avila haciéndole partícipe de la queja del cabildo catedralicio y los otros clérigos de Segovia de "que non es la pesquisa çierta nin a por que seer fecha la entrega", indicándole que aunque los pesquisidores dieran la pesquisa por cierta, si "el cabildo de la eglesia o algunos otros clerigos" le mostraban privilegios que protegieran sus bienes debía defender a éstos, no dejándolo de hacer "por que digades que non avedes poder sobre los pesquisidores e sobre los entregadores nin por otra rrazon ninguna" 29 . En este caso la pesquisa se paralizó al parecer sin contraprestación económica alguna, lo que podría deberse a que el peticionario fuera maestre Pedro, chantre de Segovia y clérigo real, al que acompañaba el canónigo Domingo Blasco. Esta buena relación del cabildo con Sancho IV sería probablemente la que facilitaría la confirmación que hiciera este monarca antes de las cortes de Haro de 1288 de dos privilegios, uno de Alfonso VII de 1150 que eximía a las propiedades del obispo y cabildo de Segovia de toda jurisdicción y dominio secular, y otro de Alfonso VIII de 1190 que ratificaba a los mismos todos los privilegios y exenciones de que gozaban, confirmaciones que obispo y cabildo solicitaron sin duda con la intención de proteger sus propiedades de una, cada vez más lejana, integración en el realengo ${ }^{30}$.

\footnotetext{
${ }^{28}$ (1287-IX-26, ¿Cáceres?), en traslado de 1287-X-21, Segovia. Archivo Catedralicio de Segovia, colección diplomática, 8-11. Ed. L.M. VILLAR GARCÍA, Documentación medieval de la catedral de Segovia (1115-1300), Salamanca, 1990, doc. 210, p. 334, que lo data erroneamente el día 27.

${ }^{29}(1287-$ IX-30, Mérida), en traslado de 1287-X-21, Segovia. Archivo Catedralicio de Segovia, colección diplomática, 8-11. Ed. L.M. VILlar GARCía, op. cit., doc. 211, p. 335.

${ }^{30}$ Respectivamente: (1288-III-26, Carrión), Archivo Catedralicio de Segovia, colección diplomática, 8-12, ed. L.M. VILlAR GARCíA, op. cit., doc. 213, pp. 339-42; y (1288-III-26, Carrión), Archivo Catedralicio de Segovia, colección diplomática, 8-13, ed. L.M. VILLAR GARCíA, op. cit., doc. 212, pp. 335-39.
} 
Estos son los últimos documentos que se conservan sobre este asunto relativos específicamente a instituciones religiosas segovianas, pues la paralización definitiva de la pesquisa de 1285 que se produjo en las mencionadas cortes de Haro, y que afectaba a todo el reino, hizo ya practicamente innecesaria cualquier gestión particular de defensa de las propiedades de abadengo. Sólo resta señalar que el nuevo talante de Sancho IV también se puede apreciar en Segovia, y así encontramos al monarca confirmando en 1290 la donación que Agustín Pérez, merced del rey, había realizado unos meses antes de varias aceñas, molinos y huertos al monasterio de San Vicente como dotación de diversos aniversarios y rezos diarios ${ }^{31}$.

\section{CONCLUSIONES}

Resulta difícil establecer de un modo definitivo las causas que motivaron el fracaso de la pesquisa de 1285 y de la política de control del abadengo establecida por Sancho IV. Lo que resulta indudable es que el problema era muy complejo y su solución dependía de un gran número de factores. Todo esto se puede apreciar en el hecho de que no hubiera avances significativos hasta el siglo XVI y la resolución del asunto no se produjera hasta el XIX.

Es muy posible que Sancho IV pretendiera un doble objetivo con su ofensiva contra el abadengo. Por un lado, la recuperación física para el realengo de toda una serie de bienes inmuebles que fortalecerían inmediatamente la situación económica del monarca, al disponer de nuevo de la propiedad de los mismos y de las rentas que éstos proporcionaban. Por otro lado, en los casos en que no fuera posible recuperar esos bienes forzar a las instituciones eclesiásticas a que pechasen por ellos y por los de nueva adquisición, de modo que el cambio de jurisdicción de las propiedades no fuera en detrimento de la hacienda regia. Sin embargo, la puesta en práctica de estas medidas, que sólo darían frutos palpables a largo plazo, era incompatible con la enorme presión que había de ejercerse sobre las instituciones eclesiásticas para invertir la tendencia que existía hasta el momento, presión que sólo podía mantenerse en el corto y medio plazo si no se quería provocar una situación de inestabilidad que habría de afectar

\footnotetext{
${ }^{31}$ (1290-I-13, Toledo), Archivo del Monasterio de San Vicente, pergaminos, $\mathrm{n}^{\circ} 10$.
} 
necesariamente al conjunto del reino. Por otro lado, aunque Sancho IV fuera consciente de las ventajas que podía proporcionarle un realengo consolidado, las necesidades de cada momento le obligaron a usar de él pues en definitiva era el mejor recurso con que contaba para hacer frente a las situaciones inesperadas. De este modo lo importante se sacrificaba una vez más en beneficio de lo inmediato.

La política de recuperación del realengo a través de un control más estricto del abadengo provocó, como era de esperar, un inmediato rechazo por parte de los eclesiásticos. Es posible que éstos inicialmente vieran peligrar la integridad de sus propiedades, pero desde el primer momento contaban con una serie de ventajas que a la postre serían definitivas. Juridicamente, las medidas contra el abadengo resultaban fáciles de rebatir rebatibles puesto que, aunque en teoría sólo el rey podía autorizar la conversión en abadengo de propiedades que no lo eran, la mayoría de las instituciones gozaban de privilegios para proteger sus adquisiciones que aunque otorgados a veces varios siglos atrás, mantenían toda su vigencia. Además, en la mentalidad colectiva de la época las donaciones a la Iglesia por motivos piadosos tenían un extraordinario arraigo y para esta época se producían todavía con una gran frecuencia, con lo que la idea de detenerlas resultaba sencillamente impensable. Por último, no hay que olvidar que los eclesiásticos eran conscientes de que el apoyo político y económico que brindaban a la monarquía resultaba imprescindible para ésta, y la celeridad con que se detuvo la pesquisa de 1285 parece indicar que no dejaron de señalárselo a Sancho IV.

El tercer estado era sin duda el que resultaba más afectado junto a la corona por el crecimiento del abadengo, puesto que el aumento de propiedades exentas disminuía por un lado los ingresos de los concejos y por otro aumentaba la presión de la fiscalidad regia sobre los mismos al disminuir el número de personas que debían hacer frente a los pechos reales. Una de las cuestiones que agudizaba el problema para los concejos era que la solución del conflicto no estaba realmente en sus manos, pues carecían de la autoridad necesaria para adoptar cualquier medida, y debían recurrir constantemente al monarca. Las únicas ocasiones en las que el tercer estado podía actuar de un modo coordinado se presentaban en las reuniones de cortes. Como se ha podido apreciar, durante el reinado de Sancho IV aprovecharon estas reuniones de un modo exhaustivo, pues en los tres ordenamientos que se conservan de este período se recogen medidas de control sobre el abadengo inspiradas sin duda en las protestas elevadas por 
los procuradores de los concejos. Resulta indiscutible que en las cortes eran escuchados por el rey sólo en función de la coyuntura política o de la coincidencia de sus postulados con las intenciones de la monarquía. A este respecto no hay más que comprobar la receptividad que sus propuestas obtenían cuando lo que se esperaba de ellos era, por ejemplo, la autorización de un servicio o el apoyo a determinada política regia. En definitiva, durante el reinado de Sancho IV el tercer estado resultó derrotado en su enfrentamiento con el estamento eclesiástico porque a diferencia de éste carecía todavía de la influencia política suficiente como para orientar las actuaciones de la monarquía.

El cuaderno de pesquisa de Segovia de 1287, por su parte, permite adentrarse en la mecánica, hasta ahora practicamente desconocida, que siguió la pesquisa sobre los bienes realengos pasados al abadengo iniciada en las cortes de Burgos de 1285 y finalizada en las de Haro de 1288, y acercarse al estudio particular del caso de la ciudad de Segovia, que como se ha podido apreciar se limita a reproducir, a una escala reducida, todas las tensiones que afectaron al reino a lo largo de este conflicto. 


\section{APÉNDICE DOCUMENTAL}

1287, agosto, 26. Segovia.

Ferrán Muñiz y Ferrán Alcher realizan una pesquisa en los registros de algunos escribanos públicos de Segovia para determinar los bienes inmuebles que habian pasado del realengo al abadengo. A continuación Diego Gil y Gutierre García entregan a Lope García de Vitoria y Martín Pérez de Burgos la posesión de diversos bienes pertenecientes a instituciones religiosas de la ciudad y la diócesis segoviana.

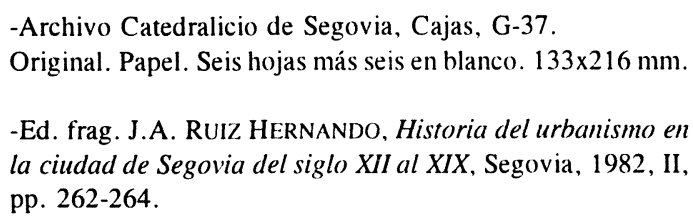

[Esto] es [borrado] [Ferrant Munn]iz e Ferrant Alcher [borrado] Segov[ia] segunt que [borrado] los rregistros de los escrivanos.

[Borrado] Caro fide [borrado] en manda en su testamento a los clerigos de la collacion de Sant Yague un huerto del logal que es çerca del rio en ffruente del huerto de Lazaro Perez por rraçon quel [borrado] un aniversario cada anno por su alma. Testigos que fueron [del testa]mento don Garcia clerigo de Sancta Trinidat, don Yague clerigo de [borrado], don Miguel clerigo de Sant Marcos, don Gil clerigo de Sant Gil, [borrado] fijo de don Pedro fijo de don Gil el arregiado, Ferrant Villada [borrado], Iohan fijo de [borrado] Iohan el sayalero. Fecha XIIII dias de octhubre era de mill e CCC e XVI annos.

Vende Garcia sobrino de don Fagunt de Marazolleja a [don Pedro cano]nigo de Parrazes unas casas con su [corral] que el [a en Ma]raçolleja en linde de Domingo Perez e de donna Maria Pedro su [borrado] por sessaenta e V [maravedies de] la guerra. Testigos don Gil [borrado], Ferrant Villada, don Pascual dagueda, don Yuannes el [borrado], Adam Perez de Requixada. Fecha XXIIII [dias de] [borrado] era de mill e CCC e XIX annos.

Vende donna [Maria] de Arevalo muger que fue de don [borrado] de Munno Pedro cerca de Parrazes a don Pedro canonigo [borrado] todo quanto ella a en este logar salvo ende las vinnas por dozientos maravedies. Testigos don Yague fide [Azlent], don [borrado] Viçeynte, Iohan Dominguez de Quadorniz, don Matheo fide Ferrant [borrado] Dominguez fide donna Melina. Fecha XXX [dias] de setiembre era de mill e CCC e XXIX annos $(l r$.$) / .$ 
Vende Gonzalo Martin de Sant Quilze a donna Maria Gonzalez abadesa del monesterio de Sant Viçeynte e al convento dese mismo monesterio, casas e vinnas e tierras e huertas [e t]odo quanto heredamiento el a en Açedos de Parrazes asi como lo conpro de Domingo de [donna] Lazarena por XXVIII maravedíes de la guerra. Testigos Matheo Perez e Gil [Iohanez] e Gonzalo Perez e Miguel Perez escrivanos e don [Iohanez] yerno de don Sancho. Fecha XIIII dias de abril era de XVII annos.

Vende don Gil de Ortigosa fijo de Domingo Abat todo quanto el a en Valsequiella al abadesa de Sant Viçeynte e a todo el convento, tierras e vinnas e solares e eras e prados e arboles por çient e novaenta maravedies de la guerra. Testigos Iohan Dominguez de la Covatiella, [Iohan] Dominguez de Sant Climente e Gonzalo Diaz, Blasco [Papon]. Mes de setienbre.

[Munno] Gomez e su muger donna Maria Domingo de la puebla de Lozoya dieron todo quanto avien al abadesa de Sant Viçeynte e a todo el convento dese monesterio con un molino en el rrio de Lozoya e con un huerto con su era que es de susso de la carrera e con todo el [...] de Val Miguel e con el [...] de Val de Perdiz e el çillero de las casas en que moran. Testigos Munno Gonzalez carrenno, Pascual Perez tenador, Domingo Perez fijo de don Mero, don Yague yerno de donna Tomea de Sant Iohan. Fecha XXIIII dias de setienbre era de XXII annos.

Vende Gonzalo Perez çapatero e su muger donna Hurraca unas casas suyas que ellos an a la collaçion de Sant Martin a don Apariçio clerigo de Sancta Trinidat e al abat de todo el cabildo $(1 \mathrm{v}$.) / de los clerigos de Segovia que son linderos de la una parte Gonzalo Perez e su muger donna Hurraca e de la otra Domingo Blasco arçipreste e las calles del rey por çient e treynta maravedies. Testigos Yague Sanchez fide don Pedro Mingo, Gomez Garcia de Sant Salvador, Garcia Dominguez de Sant Salvador, Garcia Dominguez de Sant Nicholas, Munno Garcia de Sant Martin, don Pedro de Sant Spiritu, don Salvador andador criado de Roy Perez, Estevan Perez corredor. Fecha VII dias de novienbre era de XXII annos.

Elvira Blasquez fija de Blasco Castellano dio todo quanto avie a la orden de Sancta Maria de los Huertos e entro por su familiar de la orden. Testigos Pascual Domingo e don Domingo de Marguan. Fecha XXIX dias de novienbre.

Ximena Royz monja de Sant Viçeynte dio todo quanto avie vinnas e casas e quanto heredamiento avie en Escalona al monesterio de Sant Viçeynte. Testigos don Garcia alcallde del rey, Gonzalo Perez del Escudia, Domingo Martin omme de Diago Gil, Martin Perez calçador. Fecha primer dia de dezienbre era de XXII annos.

Los clerigos de Sant Miguel an unas casas en la plaza de Sant Miguel en linde do mora Pedro Dominguez carpentero e la calle e son de la eglesia.

Registro de Pedro Perez 
Los cofrades de Sant Françisco an dize siete arançadas de viñas en Fajejas que son esta misma cofradria.

El cabildo de los clerigos de la villa an unas casas que son en la Solana que se tienen con las casas de los de Sant Roman (2 r.)/.

Vende don Lazaro de Rio Milanos e donna Maria su muger a donna Maria Gonzalez abadesa de Sant Viçeynte e al convento tres casas con su corral e con su ferren en la Matiella de Val Sequiella e obrada e media de tierra a la cabeça mesada e un huerto con sus fructos e con sus arboles e con una tierra que se tiene con el huerto por [XVI]. Testigos Iohan Dominguez escrivano, Munno Gomez, Iohan Martin escrivanos. Fecha XI dias de mayo era de XIIII annos.

Donna Hurraca la monja del monesterio de Sant Viçeynte dio unas casas al monesterio de las duennas de Sant Viçeynte que avie a la Solana que fueron de su madre donna Maria Blasco que son en linde las casas que fueron de Domingo Estevan de Araxa e las casas que fueron de Domingo Munnoz el escrivano. Era de XIX annos.

El abadesa e las duennas del monesterio de Sant Viçeynte an una azenna a la puente despinosa que dizen de la fuesa.

Los cofradres de la cofradria de Sant Blas de la puente an I huerto que es a la calleja de Mata Piojo que fue de Domingo Ponze que tiene arrendado Domingo Folgado.

Vende Pedro Estevan de Eça a ffrray Pedro prior de Sancta Maria de los Huertos casas e vinnas e huertos, prados, eras, solares, todo quanto heredamiento han el e donna Maria Perez su muger en Morata e Eça por quatro mill maravedies de la guerra. Testigos Garcia Sanchez fide Sant [sic] Garcia fide Pedro Estevan, [Iohan] de Segovia, Domingo Perez el Ruvio çapatero, Asenssio Perez, Domingo Pascual diachono de Sant Estevan, Garcia Perez corredor, don Bartolomé e don Nicholas clerigos de Sant Gil, Domingo Perez fide [Iohan] Perez (2 v.) / pelligero. Fecha XVIII dias de ffebrero era de XIX annos.

Vende Domingo Perez de los Otones yerno de donna Maria muger que fue de Miguel de Pola descalona a Ximena Royz duenna e monja de la orden de Sant Viçeynte unas casas con su corral tejadas que fueron de Domingo Loreynte en linde de Ximena Royz la dicha damas partes por çient e quarenta maravedies de la guerra. Testigos Iohan Ferrandez de la çapateria, Blasco [Sancho] andador, Yague fide Domingo Yuste pelligero, Alfonso e Pascual escrivanos. Fecha XXX dias de abril era de XVII annos.

Vende don Bernalt capellan e clerigo de Sant Pedro al cabildo de la eglesia cathedral de Segovia unas casas que a sobre la puerta de Sant Yague linderos de las casas los cofradres de Sant Andres e Simon Perez conpannero de la eglesia e la calle por çient e cinquenta maravedies de la guerra. Testigos Viceynte [Iohanez] de Sant Nicholas, Pedro Perez escrivano, Domingo Lopez alfajem, Garcia Ferrandez clerigo del coro. Fecha primero dia de mayo era XVIII annos. 
Vende Domingo [Iohanez] de Lomiello de Parrazes yerno de Munno Matheos a don Estevan abat de Parrazes X obradas de tierra e arancada e media de vinna e son las tierras en seys logares e las vinnas en dos, linda del un pedaço de la tierra Iohan Caro e linda del otro fijos de Pascual Domingo e [Iohan] Caro, linda del otro fijos de Yuan Perez e [Iohan] Caro, linda del otro Domingo [Nunno] e don Ferrando, linda del otro [Iohan] Caro e Ferrando, linda del otro el abat mismo e [Iohan] Caro, en linde del un pedazo de la vinna Domingo Gil fide Pascual Domingo e Martin Domingo fide donna Pascuala e linde del otro pedaço don Ferrando e don Gil el dicho e la meatad del arroyo en fruente de la quarta, por quarenta maravedies. Testigos Viceynte [Iohanez] alcallde, [Iohan] Martin fide Martin Calvent, [Iohan] Dominguez escrivano mayor, Domingo Martin [...]. Fecha XVII dias de agosto era de XIX annos $(3 r$ r.) $/$.

Pedro Estevan de Eça al prior e al convento de Sancta Maria de los Huertos todo quanto heredamiento avie en Monesterio de Tajunna que fue del abadesa e del monesterio de Sant Pedro de Alfiz de Toledo, solares, casas e huertas por mill maravedíes. Testigos [Iohan] Gonzalez fide don Andres e Gomez Munnoz de Sant Estevan, Roy Sanchez de Sant Millan, Yague Sanchez de Sant Climent, don Yuste peligero, Nicholas Perez escrivano. Fecha primer dia de mayo era de XXII annos.

Vende Dios Ayuda çapatero a Garcia Ferrandez clerigo que lo compro paral cabildo de los clerigos de la villa dos arançadas de çumacar en la Lastra, linde Matheo Perez e Domingo Viçeynte e las monjas de Sant Viçeynte por çient maravedies. Testigos Ferrant Abat, [Iohan] Martin de la Plaza, Domingo Blasco tenador, Domingo Martin yerno de don Yague de Azbert. Fecha XVII dias de abril era de XXIII annos.

Del rregistro de Miguel Perez

Vende Ferrant Martinez clerigo de Sant Iohan a Assenssio Perez clerigo de Sant Polo e abat del cabildo de los clerigos del sexmo de Sant Lorente e a don Adam clerigo de Sant Roman a dos por el cabildo dicho unas casas que a a la collaçion de Sant Iohan en linde de fijos de don [Rodrigo] fide Hurraca [Sancho] e de los canonigos de Sancta Maria por çient maravedies de la guerra. Testigos Domingo Viceynte de Cal de Gascos, don Matheo [corrano], don Iohan de la Puente e Domingo Perez el pastor, Mames andador, Gil Gonzalez fide Gonzalo Gil el cantero. Fecha XVII dias de março era de XVIII annos.

Ximena Sanchez duenna de Sant Viçeynte da a la orden de Sant Viçeynte todo quanto heredamiento a en Oterredondo que heredo de parte de su padre e de su madre despues de sus dias. Testigos Domingo [Iohanez] carniçero, Domingo [Iohanez] de los Molinos, Pedro Esquierdo, Alfonsso Miguel, Laza (3 v.) / ro Perez peligero, don Pedro molinero. Fecha XXIII dias de abril era de XX annos.

Vende Iohan Royz clerigo de Foyuelos a donna Rama priora de Sancto Domingo del Barbecho e al convento deste mismo logar un solar e unas casas que a en Sant Ovenna en linde del mismo e Domingo Martin fide Maria Miguel e la 
carrera por sesaenta maravedies de la guerra. Testigos Viçeynte [Iohanez] de Sant Nicholas e Elario Perez, Gonzalo Ferrandez anado de Mudriel Sanchez, Yuannes Domingo de Adradiella. Fecha V dias de febrero era de XXII annos.

La eglesia de Sant Nicholas a unas casas que son al fastial de la eglesia de Sant Nicholas, las que solie tener Mudriel Sanchez.

Vende don Matheos fide Miguel Domingo de Villa Fria e morador en Aragoneses a donna Rama priora de Sancto Domingo del Barbecho e al convento dos arançadas [mas] quarta de vinna que a en el llano en linde de don Bartolome el sochantre e de donna Lacalla muger que fue de don Matheos de [...] e en otro pedazo III quartas carrera del Nido del Aguila, linde don Bartolome sochantre e la carrera e çinco quartas en otro pedaço en linde Gil Perez sobrino de Martin Munnoz e los calonges de Parrazes por çient e ochaenta maravedies de la guerra. Testigos Ximeno Dominguez escrivano, Martin Crespo de Cal de Gascos, Miguel [Sancho] fide [Sancho] cerero, don Blasco de Sant Antolin, don Matheos fijo de Miguel Domingo. Fecha primer dia de abril era de XXIIII annos.

Vende Domingo Miguel yerno de don Lobo de Aragoneses media arançada de vinna a la dicha priora e al convento que el a carrera de la villa linde del comendador de Sant Spiritus e el pejançano e I quarta de vinna al sendero carrera de Tabladiello linde Isralel judio, (4 r.) / don Pedro fijo de don Anaya de Maraçuela por cinquenta maravedies de la guerra. Testigos los sobredichos. Fecha dia sobredicho.

El sexmo de los clerigos de Sancta Olalla an unas casas a la collaçion de Sant Yuste en linde donna Maria muger que fue de don Climent el terçero e don Blasco çapatero e que las ovieron el anno del era de mill e CCC e XXV annos.

Lope Garcia, nos Ferrant Munniz e Ferrant Alcher vos damos esta pesquisa por cierta segunt que la fallamos por los rregistros de los escrivanos publicos e que vala su derecho a cada una de las merçedes que los reyes fizieron por cartas o por privilegios a los que las tienen assi como el rey manda e que vala su derecho si algunos heredamientos pasaron de abadengo a rrengalengo por conpra o en otra manera del tiempo antes que el rey dio la sentencia en Burgos. Martes XXVI dias de agosto era de mill e CCC e XXV annos.

Yo Nicholas Perez escrivano publico a la merçed del rey en Segovia fuy presente en ffazer esta pesquisa e fiz escrivir este quaderno della por que lo falle por los registros de los escrivanos e fiz y este sig[en blanco]no en testimonio (4 v.) /.

Sepan quantos este quaderno vieren como nos Diago Gil e Gutierre Garcia damos a vos Lope Garcia de Vitoria e a vos Martin Perez de Burgos estas cosas que aqui son escriptas de la pesquisa que nos fiziemos de las cosas que pasaron de rregalengo a abadengo que vos avedes de aver segunt que nuestro sennor el rey tiene por bien e manda por sus cartas.

Damos vos unas casas e un forno e un huerto que se tiene todo en uno que es de los monges de Sancta Maria de los Huertos que son al Azoguejo so la puerta 
de Sant Iohan de que son linderos del una parte el muro de la villa e de la otra parte las casas que fueron de Lazaro Perez e de la otra parte la cal del rey e de la otra parte las casas que son de Per Diaz que fueron de donna Menga Tome e damos vos lo por cierto que lo avedes de aver.

Otrosi vos damos unas casas que fueron dadas a la orden de los ffrayles de Sanctiago que son a la collacion de Sant Sabastian de que son linderos del una parte el muro de la villa e del otra parte el huerto de Amunna Ferrandez e de su fija e del otra parte las casas en que mora Domingo Perez el pedrero e del otra parte la calle de como viene de cal de Serranos contra Sant Sabastian, salvo que finque su derecho si ellos mostraren alguna rraçon por que lo non devades aver.

Otrosi vos damos un prado que es a Sant Elario entre amas las carreras que es en linde de don Garcia e de Garcia Ferrandez su sobrino e de don Yague clerigo de Sant Yuste el qual prado fue dado a la eglesia de Sant Yuste e damos vos lo por cierto que lo avedes de aver.

Otrosi vos damos el huerto mayor que es çerca del rio de Eredma sobre la puente de Sancta Maria de los Huertos que es de los clerigos del sexmo de Sancta Trinidat en linde de los dichos clerigos e el huerto de los frayles de Sancta Cruz e del rrio de la otra parte e la calle que va contra Sancta Maria de los Huertos de la otra, salvo finque su derecho si ellos mostraren alguna rraçon por que lo non devades aver $(5 r$.) $/$.

Otrosi vos damos una casa a la collaçion de Sant Andres que Ferrant Munniz vendio al cabildo de los canonigos de Sancta Maria la eglesia mayor de Segovia la qual casa fue de donna Rebeca e de don Nicholas su fijo en linde de la una parte donna Huzeda hermana del obispo de Çipdat e de las casas de los canonigos sobredichos del otra parte, salvo finque su derecho si ellos mostraren alguna rraçon por que lo non devades aver.

Otrosi vos damos un par de casas que son en la puente castellana a la collaçion de Sant Gil que fueron dadas al dean e al cabildo de los canonigos de Sancta Maria la eglesia cathedral de Segovia e ge las dio Gomez Munnoz que son en linde de la calleja que salle de la call de Sant Gil entre estas casas e de las en que solie morar Pedro Perez clerigo e de las casas de donna Ysabel, salvo finque su derecho si ellos mostraren alguna rraçon por que lo non devades aver vos.

Otrosi vos damos unas casas que don Ximeno de Sant Andres dio a los clerigos de Sant Andres que son so las casas de donna Maria a la callalejuela çerca del canno de canno [sic] de Sant Andres e damos vos lo por çierto por que lo avedes de aver.

Otrosi vos damos unas casas en que mora Garcia Sanchez fijo de donna Rama la pescadera que son de los clerigos de Sant Miguel en linde de las casas en que solie morar Salamon de Avila e de las casas que fueron de Garcia Gonzalez del puerco de la otra parte e de la call del rey de la otra e damos vos lo por çierto que lo avedes de aver. 
Otrosi vos damos unas casas que el cabildo de los canonigos de la eglesia cathedral de Segovia an sobre la puerta de Sant Yague que les dexo don Arnalt el capellan que son en linde del una parte las $(5 \mathrm{v}$.) / casas de la cofradria de Sant Andres e de la otra parte Simon Perez conpannero de la dicha eglesia e de la calle e del capiella, salvo finque su derecho si ellos mostraren alguna rraçon por que lo non devades aver.

Otrosi vos damos arençada e media de vinna que es en Tejadiella Fonda que es en dos pedazos que fue dado al eglesia de Sant Fagunt que son linderos del un pedaço don Pedro el pedrero e de Domingo Munnoz frenero e el otro pedaço es en linde del dicho don Pedro e de la carrera que va a Avila e damos vos lo por cierto que lo avedes de aver.

Otrosi vos damos una casa e un solar que se tiene con ella que es çerca de la carneçeria de los judios que fue dada al eglesia de Sant Fagunt en linde de la una parte de las casas que fueron de Garcia Gutierrez e de las casas de los clerigos de Sant Estevan e de las casas e de las casas [sic] de don Garcia Gonzalez el mayor e de la call del rey e damos vos lo por çierto por que lo avedes de aver.

Otrosi vos damos unas casas que los clerigos del sexmo de Sant Lorent que son en el mercado en linde de amas las partes don [Iohanez] que dizen de la negriella e de la calle que va contra casa Gonzalo Munnoz e damos vos lo por çierto que lo avedes de aver.

Otrosi vos damos una huerta que las duennas del monesterio de Sant Viçeynte an en la huerta que dizen del parayso, salvo finque su derecho si ellas mostraren alguna rraçon por que lo non devades aver.

Otrosi vos damos casas e vinnas e prados e tierras que el abadesa e las duennas de Sant Viçeynte an en Fanne de Rio Moros que les ovo dado Roy Perez fijo del rromo, salvo finque su derecho si ellas mostraren alguna rraçon por que lo non devades fazer [sic] $(6 r$. $)$ /.

\section{RÉSUMÉ}

Ce travail veut donner une vue générale du conflit qui existait entre le realengo et le abadengo sous le règne de Sancho IV de Castille (1284-1295). Ce problème, qui existait entre les propriétés du roi et celles des institutions ecclésiastiques, s'était déja posé sous Alphonse $X$ et occupait une place importante parmi les affaires du royaume, place qu'il ne perdra pas durant le reste du Moyen-Âge. Après une mise en place générale du conflit et de son évolution sous le règne de Sancho IV, nous étudions son développement pendant ce règne à Ségovie, à travers d'un cuaderno de pesquisa réalisé en 1287 et qui contenait les biens immeubles reçus par les institutions religieuses ségoviennes depuis 1276. Finalement, et en raison de son caractère particulier, nous transcrivons totalement ce cuaderno de pesquisa. 


\section{SUMMARY}

This paper tries to give a general view of the conflict between the royal properties (realengo) and the church's properties (abadengo), during the reign of Sancho IV of Castile (1284-1295). This question between the king's properties and the church properties had its origin in the times of Alfonso $\mathrm{X}$ and became one of the most important affaires of Castile kingdom all along the Middle Ages. The article studies this problem in the city of Segovia, during the reign of Sancho IV, by means of a cuaderno de pesquisa, dated in 1287. This cuaderno makes it clear the properties acquired by the religious institutions in Segovia since 1276. Because of its singularity, the record is edited wholly. 